\title{
MONITORING SYSTEM OF RELATIVY HUMIDITY, CO, CO2, NH3 AND TEMPERATURE CONTROL FOR SMALL SHED
}

\author{
Diego Luis Soto Mendoza, Estudiante Ingeniería Electrónica ${ }^{1}$ \\ Javier Eduardo Martínez Baquero, Magister en Tecnología Educativa ${ }^{2}$ \\ Oscar Manuel Agudelo Varela, Magister en Ciencias de la Información y las Comunicaciones ${ }^{3}$ \\ ${ }^{1}$ Escuela de Ingeniería, Universidad de los Llanos, Colombia, diego.soto@unillanos.edu.co \\ ${ }^{2}$ Escuela de Ingeniería, Universidad de los Llanos, Colombia, jmartinez@unillanos.edu.co \\ ${ }^{3}$ Escuela de Ingeniería, Universidad de los Llanos, Colombia, oscar.agudelo@unillanos.edu.co
}

\begin{abstract}
This article presents a monitoring system of relativity humidity, carbon monoxide (CO), carbon dioxide (CO2), ammonia (NH3) and temperature control for a small shed, proposing a solution to the problem of exposure to harmful gases for the health of animals in poultry production processes. The system measures the levels of temperature, relative humidity, carbon dioxide (CO2), carbon monoxide (CO) and ammonia (NH3) using the sensors MQ-7, MQ-135 and DHT11. System acquires data from each sensor and stabilizes temperature of the environment at optimum level.
\end{abstract}

Keywords-Control, Data Acquisition, Monitoring system, Small shed, Sensors.

\section{INTRODUCTION}

It has become a necessity of the human, the improvement of its environment and the adaptation of technological tools for its efficient development in the world. From the temperature control at home where it is necessary to maintain a pleasant environment, to the industry with its mass production processes where the products must satisfy requirements of precision and cost.

Modern control simplified the design of control systems, because it is based on a model of the real system to be controlled [1].

Animal breeding processes, it is required that the control systems can maintain the environments in good conditions, so that they have a good growth and quality of life.

Regardless what is produced, such as meat, eggs, milk or other products of animal origin, it is well established that effective management of environmental conditions reduces the total cost of production. In the chicken meat business, all the components of the process, from the heavy breeders to the fattening progeny, benefit from the effective control of the environment, so it is imperative that both managers and technicians understand the basic concepts of this topic [2].

Broilers during first phase should be protected from stress by cold, especially in the winter, cold nights and early mornings. To protect animals, poultry farmers have used different strategies, including the use of several layers of curtains to increase the level of thermal insulation and reduce heat losses, also decreasing the permeability with external air.This way, it is important to pay special attention to the internal air quality of poultry houses as part of production under animal welfare parameters. Air quality should be assessed at the level of chickens and workers, specifically the concentrations of ammonia, carbon dioxide and carbon monoxide in a naturally ventilated poultry house during the first phase of broiler life [3].

Measurement of toxicity levels in environments where there is life, has a very important role in the conservation of species and industry. In this case, the majority of animal species of the poultry industry depend on a range of these conditions at the optimum level for their good development of life. What leads to having an environment like this controlled is very useful [4].

For this reason, this document shows a monitoring system of relative humidity, carbon monoxide $(\mathrm{CO})$, carbon dioxide (CO2), ammonia (NH3) and temperature control, harmful to a small shed. For this, a system for measuring said variables, temperature control, was

Digital Object Identifier (DOI):

http://dx.doi.org/10.18687/LACCEI2019.1.1.271

ISBN: 978-0-9993443-6-1 ISSN: 2414-6390

$17^{\text {th }}$ LACCEI International Multi-Conference for Engineering, Education, and Technology: "Industry, Innovation, and Infrastructure for Sustainable Cities and Communities", 24-26 July 2019, Montego Bay, Jamaica. 
designed, as well as a user interface for the entire system.

The article is divided into 3 main sections, where the first section is called "Methodology", containing information collection, system design, Controller Design, Design of the graphic interface. The second section called "Results and discussions" refers to graphic interface and finally "conclusions", where the findings are exposed after the development of the article.

\section{METHODOLOGY}

Last years, the concept of automation, defined as the application of the automatic to the control of industrial processes, has been evolving rapidly because it can improve the operations of a production process, in addition to the quality of the goods produced, guaranteeing companies achieve their objectives with optimal performance.

The automations in the industry until the 70 s were executed exclusively on the basis of relays, using what is known as wired logic, but from these years the Programmable Automations (PLCs) burst on, moving to programmed logic.

The first versions and models of PLCs were expensive, difficult to program, with relatively little memory and almost no peripheral elements. Already in the 80's these improved, both in price and in benefits, but even the programming was difficult to perform, which meant that only a small group of specialists was trained to put it into service and maintenance [5].

An automated system is made up of elements or instruments, which are used to measure physical variables, exercise control actions and transmit signals. In all processes it is absolutely necessary to control and maintain certain quantities constant [6].

The dictionary of the Real Spanish Academy defines Automatic as the discipline that deals with methods and procedures whose purpose is the substitution of the human operator by an artificial operator in the execution of a previously programmed physical or mental task [7].

One of the important aspects of the present work consists of the automation based on a PID controller implemented in a PLC, for this, it was chosen to use an evolutionary type methodology, divided into three phases, which are: Analysis, Design and Testing. The methodology also allows you to return to an earlier phase if any inconsistency or error is detected, or if you want to improve some aspect of the system.
The interface systems between user and plant based on panels of control full of light indicators, measuring instruments and push buttons, are being replaced by digital systems that implement the panel on the screen of a computer or touch screen. The direct control is carried out by the digital autonomous controllers and / or programmable automata and they are connected to a computer that performs the functions of dialogue with the operator [8].

This project was divided into three phases, as shown in figure 1 . The first consists of information collection, then a phase of system design divided into sub phases such as assembly and construction, measurement and characterization, and the design of both the driver and the user interface.

Finally, implementation and test phase.

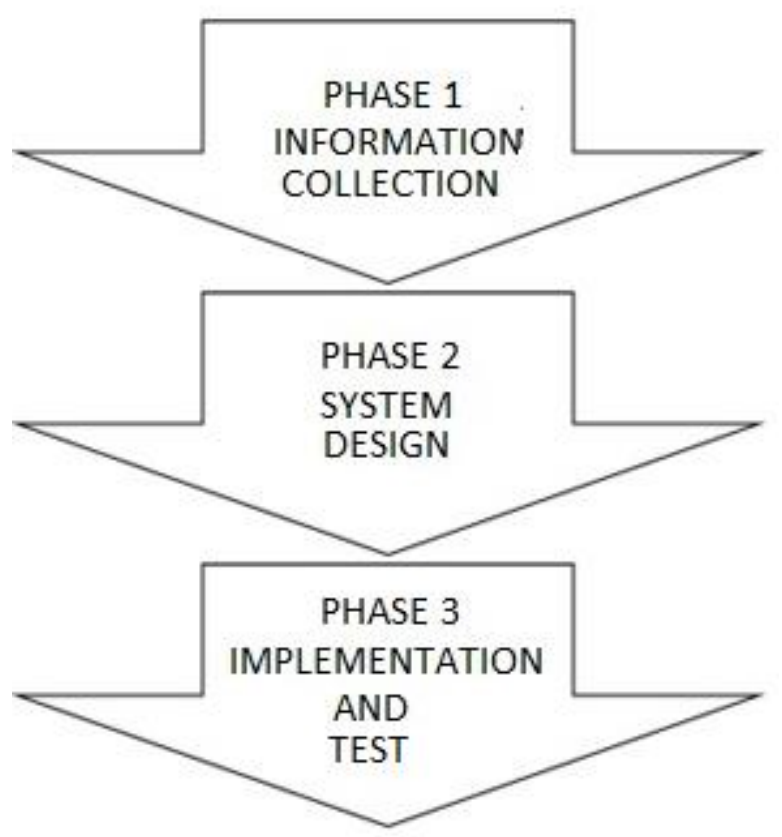

Figure 1. Phases Diagram.

Source: Authors

\section{A. First Phase: Collection information}

The first was to conduct a search for information regarding the proposed topic.

The main factors that intervene in air quality within a cage were investigated, what variables should be controlled and how to do it, in addition to previous work to have a context of what has been developed so far.

\section{B. Second Phase: System Design}

For development of the second phase, the following stages were taken into account: 


\section{MATERIALS SELECTION AND SYSTEM ASSEMBLY}

Wood structure was chosen giving a similar shape to a small shed, in which the temperature control and the measurement of the variables relative humidity, $\mathrm{CO}$, $\mathrm{CO} 2$ and $\mathrm{NH} 3$ will be implemented.

For measurements of temperature and relative humidity a DTH11 sensor was used, shown in figure 2, due to its low price and great utility. This sensor is accompanied by a module for the connection to Arduino that accurately shows the value of the temperature and relative humidity of the environment in which it is located.

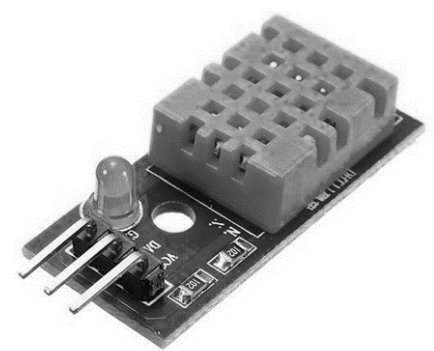

Figure 2. Temperature and relative humidity Sensor DTH11.

Measurements of harmful gases such as $\mathrm{CO}, \mathrm{CO} 2$ and $\mathrm{NH} 3$ gas sensors of the MQ family were used, as shown in figure 3 and figure 4, which bring with them an Arduino compatible module and deliver precisely the concentration in ppm (particles per million) of the gases thanks to the reaction by the interaction and contact with them [9].

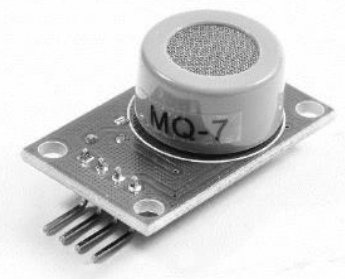

Figure 3. Carbon monoxide (CO) sensor MQ-7. Source:

https://www.olimex.com/Products/Components/Sensors/SNS-MQ7/

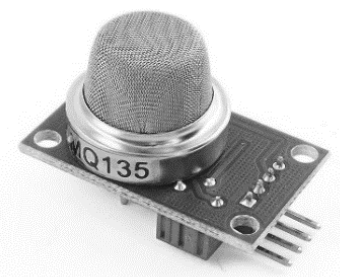

Figure 4. Carbon Dioxide (CO2) y ammoia (NH3), MQ-135.

Source: https://www.olimex.com/Products/Components/Sensors/SNSMQ135/
Figure 5 shows the reaction curves to certain gases for the sensor MQ-135, which has the ability to measure several types of gases.

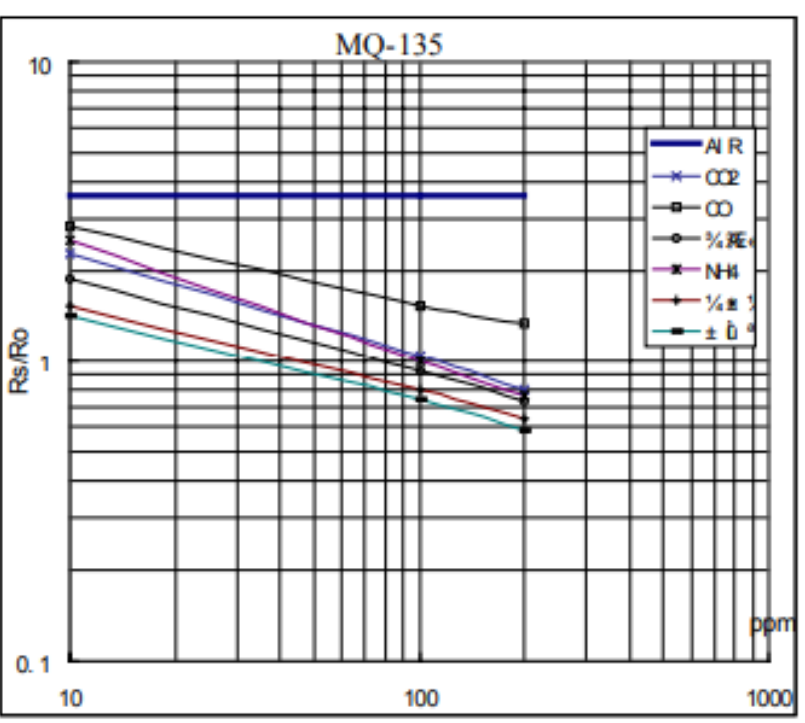

Figure 5. Reactions curves sensor MQ-135

Source: https://www.olimex.com/Products/Components/Sensors/SNSMQ135/resources/SNS-MQ135.pdf

Finally, Arduino Uno was used as a means of control and data acquisition, because of its simple use and yields good results.

Figure 6 shows the implemented system, where the central heater of the structure, the ventilation on the sides of the roof and the sensors on the sides at a certain level of height, obtaining an adequate data collection.

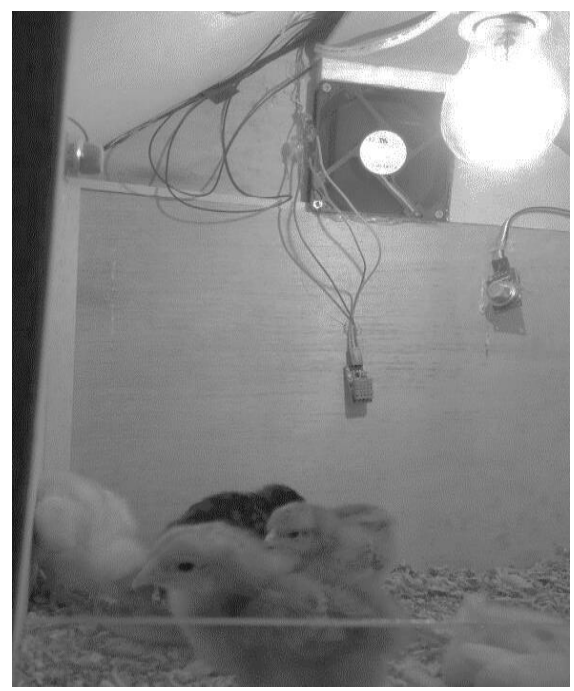

Figure 6. Small shed implemented

Source: Authors

$17^{\text {th }}$ LACCEI International Multi-Conference for Engineering, Education, and Technology: "Industry, Innovation, and Infrastructure for Sustainable Cities and Communities", 24-26 July 2019, Montego Bay, Jamaica. 


\section{A. Controller Design}

Once the controller has been identified it is important to mention that there are several design methods, among them the Ziegler Nichols tuning rules, which is based on the response of the open loop system to a step signal [10].

As an important aspect of this temperature controller, the design of a PID controller is highlighted, which will be done using the Ziegler Nichols Tuning rules, the PID controller design, according to the constants that stand out in the equation (1).

$$
P I D=\mathrm{Kp}+\frac{K i}{S}+\mathrm{KdS}
$$

These constants are indicated in table 1 and are obtained from the design process, carried out using the first method indicated by the rules.

Table I. PID Controller Tuning

\begin{tabular}{|c|c|c|c|}
\hline Type & Kp & Ti & Td \\
\hline $\mathbf{P}$ & T/L & INF & 0 \\
\hline PI & $0.9(\mathrm{~T} / \mathrm{L})$ & $\mathrm{L} / 0.3$ & 0 \\
\hline PID & $1.2(\mathrm{~T} / \mathrm{L})$ & $2 \mathrm{~L}$ & $0.5 \mathrm{~L}$ \\
\hline
\end{tabular}

Source: Ogata, Katsuhiko. Modern Control Engineering. 5th edition. Prentice Hall. Mexico

It is important to say that PID controller designed, the setpoint will be located in the range of $27^{\circ} \mathrm{C}$ to $32^{\circ} \mathrm{C}$.

Use of sensors in technology, both in the industrial and domestic field, has become usual the measurement of mechanical, thermal, electrical and chemical magnitudes in sectors such as automated industries, robotics, experimental engineering, energy saving, environmental control, automobiles, appliances, computers, are tasks that would be unthinkable without the application of sensors [11].

Modeling of the plant is described below by tuning the controller using ZIEGLER-NICHOLS, in which the plant can be described from equation (2), because it has a transport delay system:

$$
G(s)=\frac{K}{T s+1} e^{-L s}
$$

Coefficients K, T and L are obtained from system response in open loop to a step input (heating system at maximum power), as shown in figure 7 , starting from the stabilized system in $\mathrm{y}(\mathrm{t})=\mathrm{y} 0$ for $\mathrm{u}(\mathrm{t})=\mathrm{u}(0)$ a step input $u(0)$ to $u(1)$ is applied and the response of the output is recorded until it stabilizes at the new operating point.

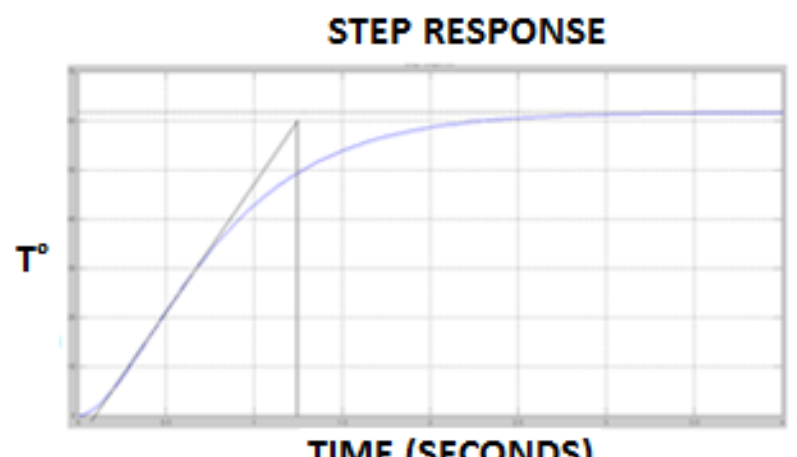

Figure 7. Exit Response to step entrance

Source: Authors

According to the parameters of Tuning, it is obtained, after the scaling:

$$
\begin{aligned}
& K=0.70 \\
& L=2.33 \\
& T=9.56
\end{aligned}
$$

Based on Ziegler-Nichols method, scaling the response of the plant, proceeds to calculate the values of the constants of the controller, achieving the following results:

$$
\begin{aligned}
\mathrm{Kp} & =4.9236 \\
\mathrm{Ti} & =4.6600 \\
\mathrm{Td} & =1.1650
\end{aligned}
$$

With the above data, the simulation of the response of the system to a single-step input is performed. Once the program is executed, the response is observed as shown in figure 8.

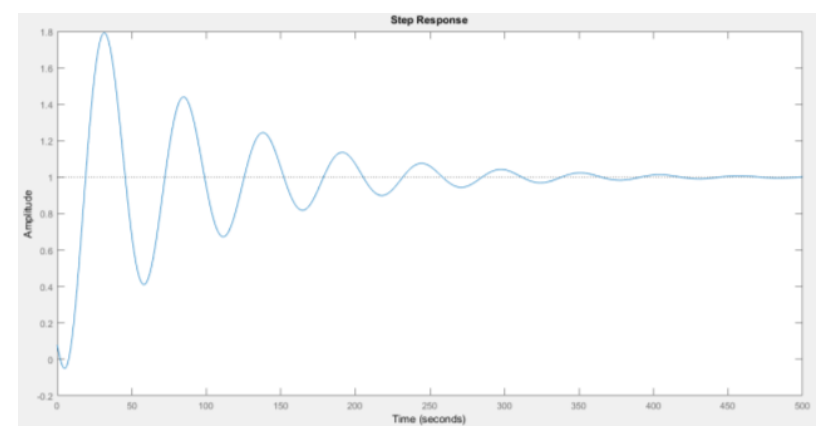

Figure. 8. Initial Response to PID Controller

Source: Authors

From figure 8 it is observed that the tuning of the found controller is necessary, specifically an adjustment 
of the integral action is required, for this reason those values are modified, the constants $\mathrm{Kp}$ and $\mathrm{Td}$ are conserved in the calculated initial value. The proposed solution shows an increase in the value of the $\mathrm{Ti}$, necessary to decrease the stable state of the output signal.

Again the simulation of the designed system is carried out, now with the following values:

$$
\begin{gathered}
\mathrm{Kp}=4.9236 \\
\mathrm{Ti}=10 \\
\mathrm{Td}=1.1650
\end{gathered}
$$

With these new values, we proceed to simulate the response of the system to a unit step input, obtaining as a result figure 9, achieving a decrease of the maximum overshot to $11.2 \%$, this being a good response, thus achieving the design of the parameters of the controller.

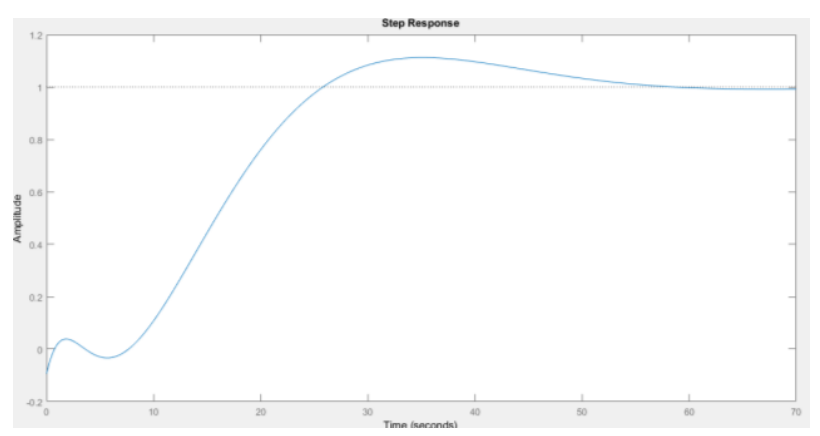

Figure 9. Modified response to PID Controller PID

Source: Authors

\section{B. Data Acquisition}

Code that indicates the libraries to be used for the DHT11 sensor is indicated below, which is the only one of the four sensors that a library uses for its operation, specifying the analog pins, read through serial port, as seen in figure 10 . void loop () \{

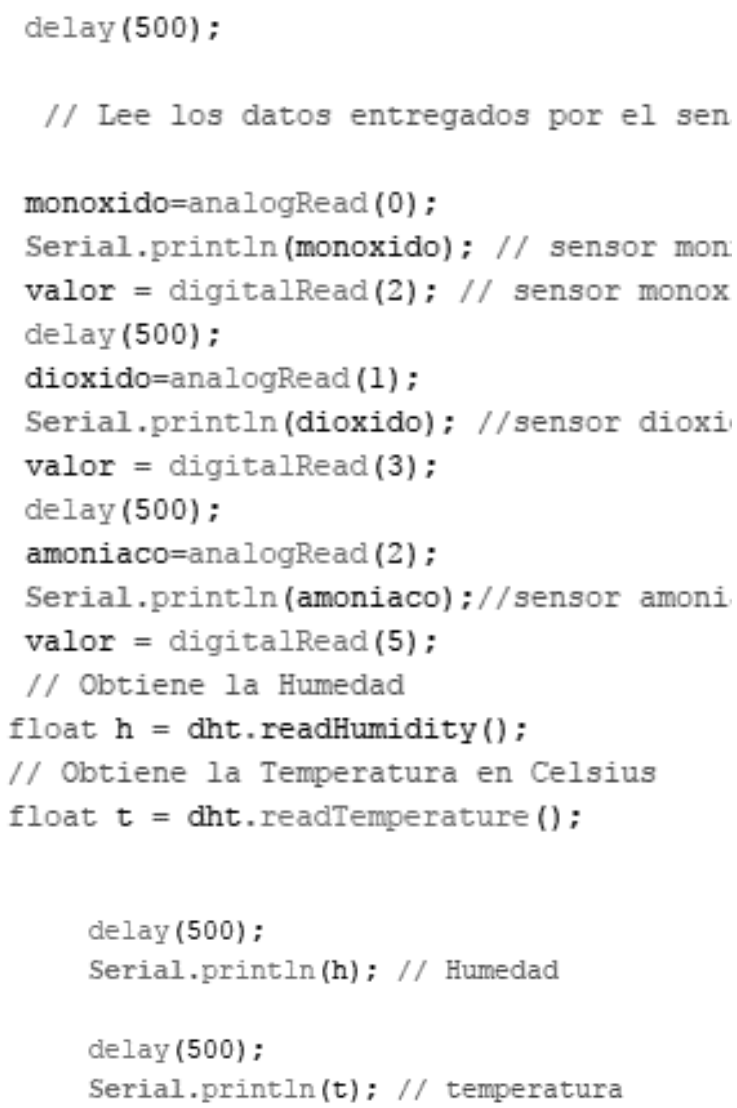

Figure 10. Arduino code, reading serial port.

Source: Authors

500 milliseconds delay is established between each measurement of the sensors to avoid errors when establishing the connection.

\section{Third Phase: Implementations and test}

\section{Graphic interface design}

Now, graphical interface design is achieved, connected by serial port with the Arduino development board, allowing the data acquisition and friendly visualization and having the possibility of graphically observing the behavior over time of the different controlled conditions.

Figure 11 shows the block diagram of the system, in which the interaction of the graphic interface is observed. 


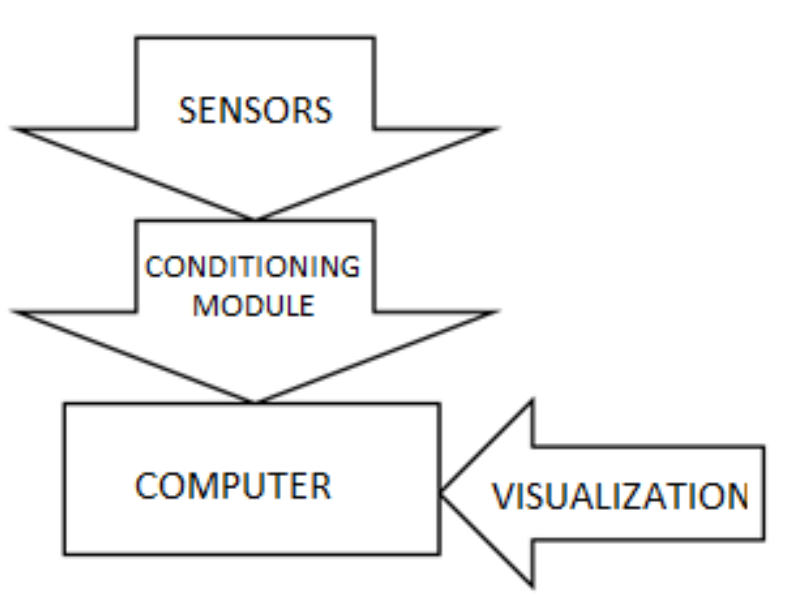

Figure 11. System Block Diagram

Source: Authors

Figure 12 shows small shed implemented, where the Arduino Uno card, power stage and ventilation is evident.

In this system the tests were carried out, finding some small problems, especially with the concentration of gases inside the shed, for that reason the datasheet was used to verify its operation and operation.

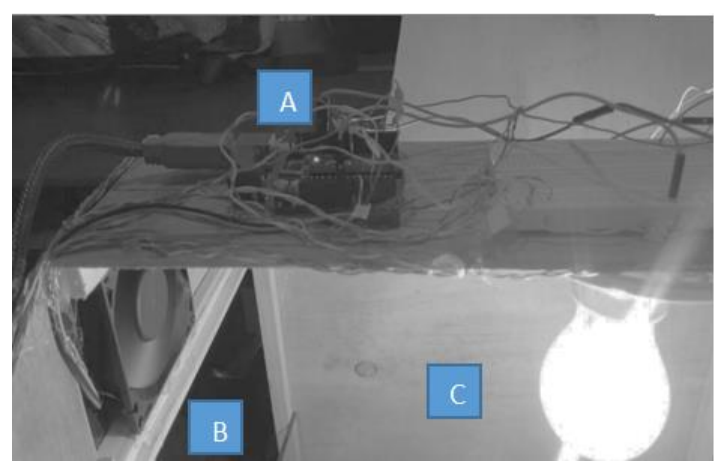

Figure 12. Control System and power (A) Arduino Uno, (B) ventilation (C) Light bulb

Source: Authors

Otherwise, the temperature controller complied with the requirements to maintain the temperature regulated.

Figure 13 shows the complete assembly with its respective parts.

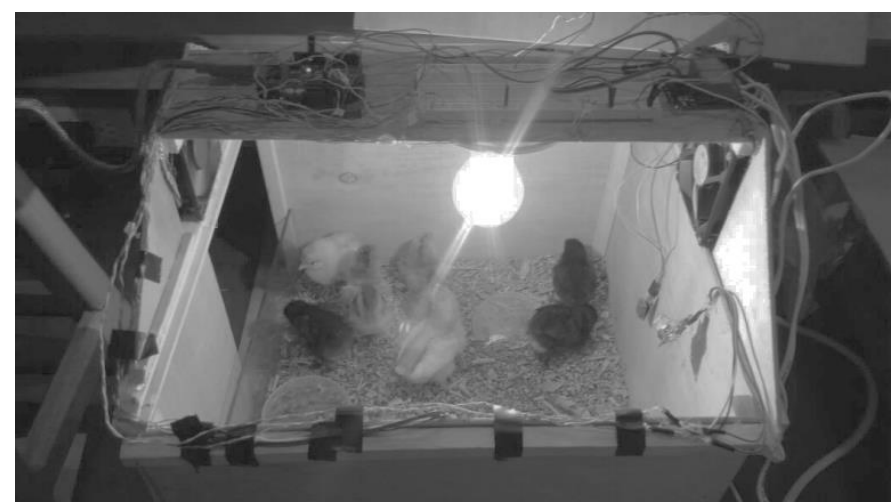

Figure 13. Shed assembled Source: Authors

\section{RESULTS AND DISCUSSIONS}

PID controller can be analyzed in many ways, one of them is the response in the time domain, or also called transitory response. From controller designed it is observed that the response of the system is quite good, characterized mainly by presenting a maximum overshoot $11.2 \%$, in addition to the rise time is only 25.9 seconds.

The following analysis consists of the location of poles in closed loop, which, to achieve stability, must be located in the left half-plane. The designed system throws the closed-loop transfer function of equation (3).

$$
\begin{aligned}
& \frac{C(s)}{R(s)} \\
& =\frac{-8.155 s^{\wedge} 5+3.236 s^{\wedge} 4+2.733 s^{\wedge} 3-2.597 s^{\wedge} 2+0.5019 s+0.09614}{87.45 s^{\wedge} 5+133.2 s^{\wedge} 4+78.05 s^{\wedge} 3+17.1 s^{\wedge} 2+1.875 s+0.09614}(3)
\end{aligned}
$$

After applying the pzmap command in MATLAB®, figure 14 is obtained, corresponding to the location of the diagram of poles and zeros of the system in closed loop.

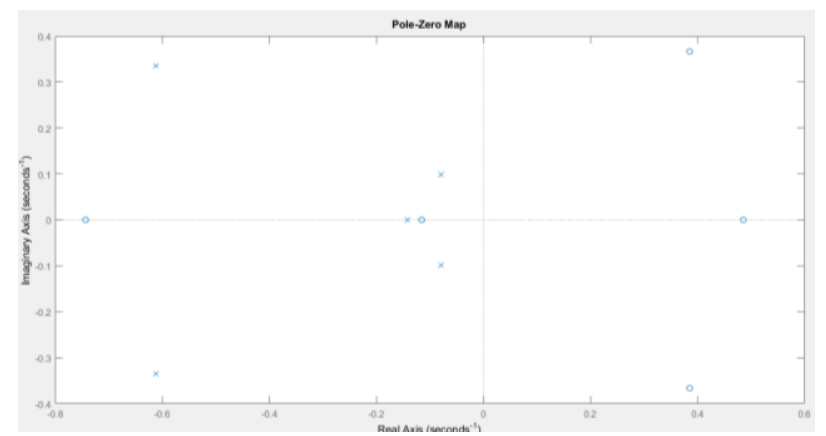

Figure 14. Diagrama de polos y ceros en lazo cerrado

$$
\text { Source: Authors }
$$

As seen in figure 16, the poles are located in the left half plane, as follows:

$$
\begin{gathered}
S_{1}=-0.143 \\
S_{2,3}=-0.0791 \pm 0.0979 i \\
S_{4.5}=-0.611 \pm 0.335 i
\end{gathered}
$$

$1^{\text {th }}$ LACCEI International Multi-Conference for Engineering, Education, and Technology: "Industry, Innovation, and Infrastructure for Sustainable Cities and Communities", 24-26 July 2019, Montego Bay, Jamaica. 


\section{ACKNOWLEDGEMENT}

The authors of the present work thank the University of the Llanos, who through the last years has significantly influenced our lives allowing us to grow as people and professionals through the development of research projects performed in the School of Engineering with the Open Technologies Research Group (GITECX), and in our case, we work looking for technological solutions that facilitate the work developed in the region of the Colombian Orinoquia.

\section{CONCLUSIONS}

Chickens in their first stage of life must be at a certain range of temperatures to survive, however, most sheds have natural ventilation, and in a tropical climate like the one in the region it is necessary to have an additional electric ventilation system to that the chickens do not suffocate and the concentration levels of the gases remain low, improving the quality of life of both chickens and workers who have contact with this type of environment.

Ziegler Nichols tuning method gets the constants to PID controller to be properly established for temperature control.

System interacts with the user, visualizing the processes in real time, in the future, the system can be implemented in large industries, control systems of environments for animals, people or others that are necessary.

Use of MQ sensors is a great alternative for small poultry producers, due to its low price and easy handling.

In Colombia, where poultry farming has a good place in the agricultural sector, it is necessary that this type of studies and projects be carried out to improve production in the future.

The air exchange allows oxygen to be replenished and helps eliminate other gases harmful to the animal, mainly carbon dioxide (CO2) and ammonia (NH3) [12].

\section{REFERENCES}

[1] Ogata, K. (2010). Ingeniería de Control Moderna. 5ta edición. Prentice Hall. México. 170-190

[2] Aviagen. Manejo del Ambiente En el Galpón de Pollo de Engorde. s.1. : Aviagen, Inc., 2009.
[3] Calidad del aire en galpón avícola con ventilación natural. Osorio, Robinson, y otros. 7, Campina Grande: Revista Brasileira de Engenharia Agrícola e Ambiental, 2016, Vol. 29. 1807-1929.

[4] Gambardella, Nicolás . Grupo de Trabajo Avícola. [En línea] Marzo de 2014. [Citado el: 13 de Septiembre de 2018.] http://www.gtavicola.com.ar/pdfs/galpones/Param etros $\% 20 \mathrm{a} \% 20$ considerar $\% 20$ en $\% 20$ galpones $\% 20$ con\%20ambiente\%20controlado.pdf.

[5] Perez, J. y M. Pineda Sánchez. (2006). Automatización de Maniobras Industriales. México. Alfaomega. pp 43-163.

[6] Creus S. A., (2006). Instrumentación industrial. Editorial Marcombo. Octava Edición, P. 594.

[7] Piedrafita M. R., (2010), Ingeniería de la Automatización Industrial. México. Alfaomega. 2da Edición ampliada y actualizada. pp. 59-80.

[8] A, Rodríguez. (2011). Sistemas SCADA. México. Alfaomega Grupo Editorial.. 2da edición. pp 3050

[9] Olimex. TECHNICAL DATA MQ-135 GAS SENSOR. [En línea] [Citado el: 13 de Septiembre de 2018.] https://www.olimex.com/Products/Components/Se nsors/SNS-MQ135/resources/SNS-MQ135.pdf.

[10] Kuo, Benjamin. Sistemas de Control Automático. México. Séptima Edición. PEARSON Prentice Hall Hispanoamericana. 1996, 897.

[11] Pallas A. R. (2005). Sensores y Acondicionadores de Señal. 4ta Edición. Marcombo. Mexico. 40-120

[12] Pantoja-Estrada, Diego. Engormix. Avicultura. [En línea] 9 de Diciembre de 2014. [Citado el: 13 de Septiembre de 2018.] https://www.engormix.com/avicultura/articulos/m anejo-temperatura-ambiental-calidad-t31776.htm.

$17^{\text {th }}$ LACCEI International Multi-Conference for Engineering, Education, and Technology: "Industry, Innovation, and Infrastructure for Sustainable Cities and Communities", 24-26 July 2019, Montego Bay, Jamaica. 